\title{
Construção e avaliação de bundle frente ao extravasamento de antineoplásicos: estudo metodológico
}

\author{
Bundle construction and assessment before antineoplastic extravasation: a methodological study \\ Construcción y evaluación de bundle ante la extravasación de antineoplásicos: estudio metodológico
}

João Marcos Alves Melo ${ }^{1}$ ic https://orcid.org/0000-0002-9056-6782

Patricia Peres de Oliveira' ${ }^{1}$ id https://orcid.org/0000-0002-3025-5034

Andrea Bezerra Rodrigues ${ }^{2}$ iD https://orcid.org/0000-0002-2137-0663

Raíssa Silva Souza ${ }^{1}$ id https://orcid.org/0000-0001-5010-763X

Deborah Franscielle da Fonseca ${ }^{1}$ is https://orcid.org/0000-0001-6001-2837

Thaís Fonseca Gontijo ${ }^{1}$ io https://orcid.org/0000-0003-3021-5267

Edilene Aparecida Araújo da Silveira ${ }^{1}$ io https://orcid.org/0000-0001-7378-2240

Melo JM, Oliveira PP, Rodig Como citar:

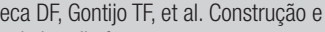
valiação de bundle frente ao extravasamento de antineoplásicos: estudo metodológico. Acta Paul Enferm. 2020;33:eAPE20190075.

DOI http://dx.doi.org/10.37689/ acta-ape/2020A00075

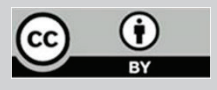

Descritores Derapêuticos e diagnósticos; Antineoplásicos; Cuidados de enfermagem; Enfermagem oncológica

Keywords

Extravasation of diagnostic and therapeutic materials; Antineoplastic agents; Nursing care;

Oncology nursing

Descriptores

Extravasación de materiales terapéuticos y diagnósticos; Antineoplásicos; Atención de enfermería; Enfermería oncológica

Submetido 1 de Abril de 2019

Aceito

4 de Outubro de 2019

Autor correspondente

Patrícia Peres de Oliveira

E-mail: pperesoliveira@gmail.com

\section{Resumo}

Objetivo: Construir e avaliar o conteúdo de um bundle de prevenção e condutas frente ao extravasamento de agentes antineoplásicos em pacientes oncológicos adultos.

Métodos: Estudo metodológico, em três etapas: realização de Scoping Review, construção do bundle e avaliação do material por especialistas. Foi desenvolvido segundo o referencial metodológico da psicometria de Pasquali. Ressalta-se que o bundle foi dividido em um módulo com medidas de prevenção do extravasamento de antineoplásicos e outro módulo com condutas frente ao extravasamento. Para avaliação de conteúdo, aplicou-se a técnica de Delphi em duas rodadas (Delphi I [13 juízes] e Delphi II [nove juízes]) e considerou-se válidos aqueles itens com Coeficiente de Validação de Conteúdo (CVC) maior que 0.78 e consenso de mais de $80,0 \%$. Os dados foram analisados através de estatística descritiva e inferencial (Teste binominal).

Resultados: Todos os requisitos do bundle alcançaram concordância entre os juízes superior a 80,0\%, bem como todos os itens alcançaram níveis de avaliação estatisticamente significativos. Ao final do Delphi II, os dois módulos do bundle se apresentaram expressivamente válidos (prevenção do extravasamento de antineoplásicos [CVC $=0,93]$ e condutas frente ao extravasamento [CVC $=0,96]$ ).

Conclusão: 0 conteúdo do bundle demonstrou alta credibilidade e, sua adoção nas instituições de saúde, pode contribuir para a qualidade da assistência e das condutas dos profissionais frente ao extravasamento de agentes antineoplásicos em pacientes oncológicos adultos.

\section{Abstract}

Objective: To construct and assess the content of a prevention and management bundle regarding the extravasation of antineoplastic agents in adult cancer patients.

Methods: There were three-step methodological study: Scoping Review, bundle construction and expert material assessment. It was developed according to the methodological framework of Pasquali psychometry. It is noteworthy that the bundle was divided into a module with measures to prevent antineoplastic extravasation and another module with conduits before extravasation. For content assessment, the Delphi technique was applied in two rounds (Delphi I [13 judges] and Delphi II [nine judges]) and those items with Content Validation Coefficient (CVC) greater than 0.78 and more than $80.0 \%$ consensus. Data were analyzed using descriptive and inferential statistics (Binominal Test).

Results: All bundle requirements reached agreement among judges greater than $80.0 \%$, and all items achieved statistically significant assessment levels. At the end of Delphi II, both bundle modules were expressively valid (prevention of antineoplastic extravasation [CVC $=0.93$ ] and ducts before extravasation [CVC $=0.96]$ ). 
Conclusion: Bundle content has demonstrated high credibility and its adoption in health institutions can contribute to the quality of care and conduct of professionals facing the extravasation of antineoplastic agents in adult cancer patients.

\section{Resumen}

Objetivo: Construir y evaluar el contenido de un bundle (conjunto de medidas) de prevención y conductas ante la extravasación de agentes antineoplásicos en pacientes oncológicos adultos.

Métodos: Estudio metodológico, en tres etapas: realización de Scoping Review, construcción del bundle y evaluación del material por especialistas. Fue desarrollado según la referencia metodológica de la psicometría de Pasquali. Se resalta que el bundle fue dividido en un módulo con medidas de prevención de la extravasación de antineoplásicos y otro módulo con conductas ante la extravasación. Para la evaluación del contenido se aplicó el método Delphi en dos rondas (Delphi I, 13 jueces, y Delphi II, 9 jueces) y se consideraron válidos aquellos ítems con Coeficiente de Validez de Contenido (CVC) mayor a 0,78 y consenso de más de 80,0\%. Los datos fueron analizados a través de estadística descriptiva e inferencial (Prueba binominal).

Resultados: Todos los requisitos del bundle lograron una concordancia superior a 80,0\% entre los jueces, así como todos los ítems alcanzaron niveles de evaluación estadísticamente significativos. Al final del Delphi II, los dos módulos del bundle demostraron ser significativamente válidos (prevención de la extravasación de antineoplásicos, $\mathrm{CVC}=0,93$, y conductas ante la extravasación, $\mathrm{CVC}=0,96$ ).

Conclusión: El contenido del bundle demostró una alta credibilidad y su implementación en instituciones de salud puede contribuir a la calidad de la atención y de las conductas de los profesionales ante la extravasación de agentes antineoplásicos en pacientes oncológicos adultos.

\section{Introdução}

O extravasamento de agentes antineoplásicos (AA) é definido como a instilação ou vazamento não intencional desses AA no espaço perivascular e/ou tecidos circunjacentes, é considerado uma emergência oncológica, devido ao potencial de alguns fármacos de acarretar danos ao paciente. O grau de dano local depende principalmente da toxicidade do respectivo composto e da quantidade de droga extravasada. ${ }^{(1,2)}$

A incidência de extravasamento varia muito. Estimativas entre 0,01\% e 7\% são observadas em várias publicaçóes, contudo quando analisado o número de eventos adversos (EA) associados à terapia antineoplásica (TA), o número absoluto de extravasamentos torna-se expressivo, visto que o resultado pode ser potencialmente avassalador, com implicaçôes a longo prazo, tais como, precisão de cirurgia reconstrutiva e danos permanentes em nervos, ou seja, tem capacidade de ser mais extenuante e debilitante para o paciente do que sua enfermidade primária. ${ }^{(3-5)}$

Desse modo, a toxicidade dermatológica decorrente do extravasamento de (TA) constitui um dos principais EA que exigem cuidado intensivo do enfermeiro, em virtude de exercer um papel primordial na prevenção, identificação e no acompanhamento das complicaçôes desse EA. Estudos apontam que a maioria dos extravasamentos pode ser evitada com a implementação sistemática de técnicas de administração cuidadosas, padronizadas e baseadas em evidências e, para minimizar o risco de extravasamento, os enfermeiros envolvidos na infusão e no manejo de drogas citotóxicas precisam ser treinados, além de construírem e implementarem protocolos e bundles preventivos e na gestão dos extravasamentos. ${ }^{(4-6,7)}$

$\mathrm{O}$ cuidar, em enfermagem, inclui planejar e realizar intervençóes para melhorar as respostas das pessoas aos problemas de saúde e aos processos da vida. Requer a identificação de respostas funcionais e disfuncionais, a proposição de intervençôes e a avaliação de resultados obtidos. ${ }^{(8)}$ A melhor forma de melhoria dos processos e otimização do atendimento ao paciente vítima de extravasamento é a utilização de bundles. Destarte, o bundle é uma maneira estruturada de melhorar os processos de atendimento e os resultados do paciente, ou seja, um conjunto de práticas baseadas em evidências, quando realizadas coletiva e confiavelmente, comprovadamente melhoram os resultados dos pacientes. ${ }^{(8,9)}$

Nessa perspectiva, a Resolução do Conselho Federal de Enfermagem, número 569 de 2018, ${ }^{(10)}$ que regulamenta a atuação dos profissionais de enfermagem em quimioterapia antineoplásica, dentre funçôes específicas dos enfermeiros, está a elaboração de protocolos terapêuticos na prevençáo, tratamento e minimização dos efeitos colaterais e, os bundles têm sido largamente divulgados nas instituiçóes hospitalares, uma vez que quando implementados são eficazes na prevenção e redução eventos adversos. ${ }^{(9,10)}$

Diante do exposto, a prevenção e o manejo frente ao extravasamento de AA em pacientes oncológicos adultos é primordial para qualidade do cuidado prestada, em virtude de ser uma intercorrência grave que gera estresse na equipe de enfermagem e, pode 
gerar danos irreversíveis ao paciente. ${ }^{(11)}$ Observou-se escassez de estudos internacionais e nenhum nacional nos últimos anos que sintetizassem as evidências, disponíveis na literatura, no contexto da prevenção e conduta frente ao extravasamento de TA.

A relevância deste estudo está em fornecer um bundle com as principais medidas visando a prevenção e condutas frente ao extravasamento de AA e, assim, contribuir substancialmente para a prestação de uma assistência de qualidade e livre de danos para a pessoa com neoplasia maligna em tratamento com TA. Destaca-se que enfermeiros que administram AA necessitam estar cientes das evidências mais atuais para os múltiplos tipos de tratamento de extravasamento, além da prevenção dos extravasamentos de TA.

Nessa lógica, esta pesquisa teve como objetivo construir e avaliar o conteúdo de um bundle de prevenção e condutas frente ao extravasamento de agentes antineoplásicos em pacientes oncológicos adultos.

\section{Métodos}

Trata-se de estudo metodológico, fundamentado no referencial metodológico da psicometria de Pasquali, ${ }^{(12)}$ desenvolvido em três etapas: realização de scoping review, construção do bundle e avaliação de conteúdo do instrumento por juízes/expertises, no período de maio a novembro de 2018 .

Inicialmente, foram utilizados os resultados provenientes da revisáo de literatura, com vistas a identificação das evidências científicas sobre prevenção e conduta do enfermeiro frente ao extravasamento de quimioterápicos antineoplásicos em pacientes adultos, por meio de scoping review (conforme as recomendaçóes do guia internacional PRISMA-ScR ${ }^{(13)}$ e no método proposto pelo Joanna Briggs Institute, Reviewers Manual 2017), (14) baseada em evidências científicas nacionais e internacionais (Apêndice 1).

A etapa da construção do bundle, contou, inicialmente, com 64 itens, distribuídos em dois módulos: o primeiro módulo enfocou medidas de prevenção do extravasamento de antineoplásicos em pacientes adultos oncológicos e, foi subdivido em cinco modalidades: 1) aquelas açóes preventivas quanto ao paciente, 2) quanto ao dispositivo adequado para punção, 3) quanto ao local de punção, 4) quanto à infusão e 5) quanto a equipe de enfermagem.

O segundo módulo dirigiu-se as condutas frente ao extravasamento de antineoplásicos em pacientes adultos oncológicos. Foi subdivido em três modalidades: 1) as instruçôes gerais, 2) as instruçôes específicas e 3) modo de utilização dos antídotos e compressas. Cada modalidade teve os seus respectivos itens (que foram identificados por uma letra ou número em ordem crescente).

Conforme a prática baseada em evidências, os trabalhos foram analisados e classificados de forma hierárquica segundo a proposta de Melnyk e FineoutOverholt ${ }^{(15)}$ que organiza os níveis de evidência em: nível I - oriundas de revisão sistemática ou metanálise de ensaios clínicos randomizados, controlados ou de diretrizes clínicas baseadas em revisôes sistemáticas de ensaios clínicos randomizados controlados; nível II - derivadas de, pelo menos, um ensaio clínico randomizado controlado bem delineado; nível III - obtidas de ensaios clínicos bem delineados sem randomização; nível IV - provenientes de estudo de coorte e de caso-controle bem delineados; nível V - originárias de revisão sistemática de estudos descritivos e qualitativos; nível VI - derivadas de um único estudo descritivo ou qualitativo; nível VII - provenientes de opinião de autoridades e/ou relatórios de comitê de especialistas. ${ }^{(15)}$

Cada um desses módulos foi avaliado quanto aos critérios da avaliação estabelecidos por Pasquali: ${ }^{(12)}$ comportamento, objetividade, simplicidade, clareza, relevância, precisão, variedade, modalidade, tipicidade, credibilidade, amplitude e equilíbrio. Ressalta-se que havia um quadro esclarecendo sobre cada um desses 12 critérios e, os mesmos foram avaliados por meio da escala de Likert, sendo: "1 - inadequado (I)", classificado como grau de discordância; "2 - parcialmente adequado (PA)"; "3 - não tenho certeza $(\mathrm{N})$ ", classificados como grau de indecisão; "4 - adequado (A)" e "5 - totalmente adequado (TA)", ambos como grau de concordância.

$\mathrm{Na}$ etapa de avaliaçáo do bundle, a fim de se alcançar o quantitativo de juízes recomendados por Pasquali, ${ }^{(12)}$ ou seja, seis a 20 expertises, decidiu-se convidar um número maior, ponderando que alguns poderiam não responder ou recusar o convite. 
Esse processo foi direcionado por meio da análise de juízes selecionados para o estudo, escolhidos de forma intencional, por meio da apreciação de currículos na Plataforma Lattes do Conselho Nacional de Desenvolvimento Científico e Tecnológico (CNPq). Para isso, utilizou-se o formulário de busca simples, no Campo "buscar por", na Categoria "assunto", por meio do uso dos termos "oncologia" el ou "quimioterapia”. Identificaram-se 325 doutores.

Para a triagem dos possíveis juízes, o modelo de Fehring $^{(16)}$ foi adaptado e utilizado, uma vez que confere uma pontuaçáo máxima de 14 pontos, contudo, para essa seleção foi atribuído um escore mínimo de cinco pontos, a saber: mestrado e doutorado em enfermagem em enfermagem ou áreas afins (critério obrigatório), dissertação abordando cuidados oncológicos (2 pontos), tese com tema em oncologia (2 pontos), certificado ou título de especialista em Enfermagem oncológica (1 ponto), pesquisa (s) na área de oncologia no últimos cinco anos (3 pontos), autoria em pelo menos dois artigos, nos últimos dois anos, na área oncológica (3 pontos), experiência em TA e oncologia de pelo menos três anos (3 pontos). ${ }^{(16)}$

Após a busca, chegou-se a um total de 40 juízes elegíveis. Estes receberam carta convite por e-mail, tendo um prazo de até 20 dias para devolução do instrumento; além do Termo de Consentimento Livre e Esclarecido (TCLE), com as devidas instruçóes para realizar a análise e avaliação. $\mathrm{O}$ instrumento a ser preenchido para a avaliação foi construído na ferramenta Google Docs, com informaçóes iniciais de caracterização do participante e os itens do instrumento. Cada item tinha um espaço no qual os juízes poderiam fornecer sugestóes de mudança e melhoria.

Esse processo foi conduzido pela técnica Delphi. Dessa forma, os especialistas responderam, por meio de rodadas, a um questionário avaliativo. Dos 40 possíveis juízes inicialmente selecionados, 13 aceitaram participar da avaliação do bundle, correspondeu à primeira rodada (Delphi I), quando houve sugestôes de alteração no material para o seu aprimoramento. As modificaçóes consideradas pertinentes e, após ajustes, o feedback das respostas foi enviado junto com o protocolo, configurando a segunda rodada (Delphi II), etapa em que houve a participação de nove juízes (ressalta-se que estes nove juízes participaram das duas rodadas de Delphi).

Para a avaliação do bundle, as avaliaçóes dos juízes foram inseridas no banco de dados do Microsoft Excel $2016^{\circ}$ e após analisadas, onde se verificou as pontuaçôes atribuídas a cada item. A relevância dos itens foi obtida pela aplicação do Coeficiente de Validade de Conteúdo (CVC). ${ }^{(15)}$ Considerou-se válido o item que apresentasse mais de $80 \%$ de concordância entre os juízes (avaliado como adequado) e um Coeficiente de Validade de Conteúdo (CVC) > 0,78. ${ }^{(17)}$

Ademais, foi realizada a análise descritiva e inferencial (teste binomial). O consenso entre os juízes e os escores do CVC alcançados nas rodadas de Delphi. Para tanto, adotou-se o $\rho$-valor $\leq 0,05$ como parâmetro para a significância estatística.

O estudo foi aprovado pelo Comitê de Ética em Pesquisa da Universidade Federal de São João del-Rei, parecer de número: 2.010.532 e, trata-se de um subprojeto de uma pesquisa "guarda-chuva" intitulada "construção coletiva de protocolos e manuais", desenvolvida pelo grupo pesquisa "oncologia ao longo do ciclo de vida”, registrado no diretório de grupo de pesquisa do Conselho Nacional de Desenvolvimento Científico e Tecnológico (CNPq).

Importa ressaltar que a validação externa do bundle ainda não foi realizada, uma vez que se trata da elaboração de um instrumento que, somente após a sua implementação, deverá ser reavaliado e nele promovidas as adequaçóes necessárias, conferindo maior consistência e representatividade ao mesmo. A sua implementação exige a capacitação dos profissionais que irão utilizá-lo, seguida de avaliaçôes periódicas sobre o seu uso.

\section{Resultados}

Na construção do bundle, evidenciou-se que, ao formato inicial não foram acrescidos itens previamente elencados. As alterações realizadas consistiram, essencialmente, na objetividade (as recomendaçóes permitem que se alcance o objetivo desejado), na simplicidade (os itens expressam uma única ideia e permitem compreensão adequada), na clareza (o conteúdo é explicitado de forma clara e inequívo- 
ca), na precisão (cada item do instrumento é distinto dos demais, não se confundem) e na modalidade (vocabulário é adequado, sem gerar ambiguidades) e; resultaram em aumento na concordância. O bundle finalizado contou com 57 itens distribuídos nos dois módulos (Apêndice 2).

No processo de avaliação, o comitê de especialistas foi composto por 13 profissionais na primeira rodada de avaliação e nove na segunda, com perda de dois devido a não devolução do instrumento. Participaram doutores com experiência prática na oncologia e na docência, idade mínima dos especialistas foi de 35 anos e máxima de 58 anos (média $=40,12$ e desvio padrão=6,75 em Delphi I; média $=42,71$ e desvio padrão=7,80 em Delphi II), cujo tempo de formação média foi de 20,20 e desvio padrão=5,81 em Delphi I; média=19,64 e desvio padrão= 5,84 em Delphi II. Exerciam a profissão em quatro das três regióes brasileiras (Tabela 1).

Tabela 1. Caracterização dos juízes participantes das fases Delphi I e Delphi II

\begin{tabular}{lcc}
\hline Caracterização dos juízes & Delphi I $(\mathbf{n}=13) \mathbf{n}(\%)$ & Delphi II $(\mathbf{n}=9) \mathbf{n}(\%)$ \\
\hline Sexo & & \\
Masculino & $2(15,4)$ & $2(22,2)$ \\
Feminino & $11(84,6)$ & $7(77,8)$ \\
Área que trabalha atualmente & & \\
Docência & $8(61,5)$ & $7(77,8)$ \\
Assistência e Docência & $4(30,8)$ & $1(11,1)$ \\
Docência e Gestão & $1(7,7)$ & $1(11,1)$ \\
Tempo de formado em Enfermagem & & \\
11 a 20 anos & $7(53,6)$ & $5(55,6)$ \\
21 a 30 anos & $5(38,7)$ & $3(33,3)$ \\
Mais de 30 anos & $1(7,7)$ & $1(11,1)$ \\
Tempo de atuação na área de & & \\
oncologia & & $1(11,1)$ \\
Até 10 anos & $1(7,7)$ & $4(44,5)$ \\
11 a 20 anos & $6(45,9)$ & $3(33,3)$ \\
21 a 30 anos & $5(38,7)$ & $1(11,1)$ \\
Mais de 30 anos & $1(7,7)$ & $8(88,9)$ \\
Região em que atua & & $1(11,1)$ \\
Sudeste & $11(84,6)$ & $0(0,0)$ \\
Nordeste & $1(7,7)$ & \\
Sul & $1(7,7)$ & \\
\hline
\end{tabular}

A tabela 2 descreve o consenso final entre os juízes quanto aos itens analisados de conteúdo do bundle de prevenção frente ao extravasamento de $\mathrm{AA}$, que obtiveram concordância ("adequado" e "totalmente adequado"), de acordo com os critérios de avaliação de Pasquali.

Segundo o exposto na tabela 2, observou-se que, encontrava-se abaixo do preconizado nas medidas/ ações de prevenção, para que o bundle fosse considerado válidos no Delphi I os itens: quanto ao paciente, somente o requisito referente a modalidade (69,2\%); em relação dispositivo adequado para punção, os itens clareza $(69,2 \%)$ e precisão (76,9\%); quanto ao local da punção do acesso venoso, os incisos simplicidade $(53,8 \%)$, clareza $(69,2 \%)$, precisão $(76,9 \%)$ e modalidade (69,2\%); no que concerne à infusão de antineoplásicos, os itens objetividade (53,8\%), simplicidade (76,9\%) e clareza (76,9\%); quanto à equipe de enfermagem, o requisito modalidade (76,9\%). Destaca-se que os itens supracitados não apresentaram significância estatística na concordância entre os juízes. Cabe destacar que as sugestóes dos juízes na primeira rodada (Delphi I) para os itens que necessitaram ser revistos foram quanto à sua forma de apresentação, exclusão, realocação ou condensação. No bundle de prevenção as solicitaçóes realizadas foram: nas medidas de prevenção "quanto ao paciente", o vocabulário foi adequado, a fim de não gerar ambiguidades (na letra a foi explanado quais as possíveis alteraçóes dérmicas).

Nas ações "quanto ao dispositivo", o conteúdo foi explicitado de forma clara, inequívoca e relevante (unido em um único item - letra $\mathrm{D}$ - dar preferência a cateteres de materiais flexíveis, tais como polietileno, siliconizado, Vialon ${ }^{\mathrm{TM}}$ e nunca utilizar cateter agulhado para administração de $\mathrm{AA}$ vesicante em via periférica); nos itens "quanto ao local da punção do acesso venoso", houve realocação e condensação para possibilitar a expressam de uma única ideia, permitir compreensão adequada e adequação do vocabulário, sem gerar ambiguidades (na letra $\mathrm{d}$ foi condensado todos dez pontos importantes para a seleção do local para a inserção do cateter venoso periférico e realocado em letra separada (f) - realizar flushing (lavagem com pressão do cateter) com solução fisiológica $0,9 \%$, logo após a inserção do mesmo para testar sua funcionalidade e durante a infusão, observar surgimento de edema local e relato de dor local pelo paciente). No que concerne "quanto à infusão" de TA, as recomendaçóes permitiram que se alcançasse o objetivo desejado e foi indicado modificação em relação à administração de antieméticos apenas após a TA, sendo retirado esse item devido falta de evidência concisa. Nas ações "quanto à equipe de enfermagem", o vocabulário foi acertado, de modo que não gerasse ambiguidades. No Delphi II, todos os 
Tabela 2. Consenso entre os juízes nas etapas Delphi I e II para os itens avaliados de conteúdo do bundle de prevenção frente ao extravasamento de agentes antineoplásicos em pacientes oncológicos adultos

\begin{tabular}{|c|c|c|c|c|c|c|c|c|c|c|}
\hline \multirow{3}{*}{ Itens } & \multicolumn{10}{|c|}{ Ações/Medidas de Prevenção } \\
\hline & \multicolumn{2}{|c|}{ Quanto ao paciente } & \multicolumn{2}{|c|}{ Quanto ao dispositivo } & \multicolumn{2}{|c|}{ Quanto ao local de punção } & \multicolumn{2}{|c|}{ Quanto à infusão } & \multicolumn{2}{|c|}{$\begin{array}{l}\text { Quanto à equipe de } \\
\text { enfermagem }\end{array}$} \\
\hline & $\begin{array}{c}\text { Delphi I } \\
(\rho \text {-value })\end{array}$ & $\begin{array}{c}\text { Delphi II } \\
\left(\rho \text {-value }{ }^{\star}\right)\end{array}$ & $\begin{array}{c}\text { Delphi I } \\
\left(\rho \text {-value }{ }^{\star}\right)\end{array}$ & $\begin{array}{c}\text { Delphi II } \\
(\rho \text {-value })\end{array}$ & $\begin{array}{c}\text { Delphi I } \\
(\rho \text {-value })\end{array}$ & $\begin{array}{c}\text { Delphi II } \\
\left(\rho \text {-value }{ }^{\star}\right)\end{array}$ & $\begin{array}{c}\text { Delphi I } \\
(\rho \text {-value })^{\star}\end{array}$ & $\begin{array}{c}\text { Delphi II } \\
(\rho \text {-value })\end{array}$ & $\begin{array}{c}\text { Delphi I } \\
\left(\rho \text {-value }{ }^{\star}\right)\end{array}$ & $\begin{array}{c}\text { Delphi II } \\
\left(\rho-\text { value }^{\star}\right)\end{array}$ \\
\hline Comportamento & $\begin{array}{c}92,3 \% \\
(0,003)^{\star \star}\end{array}$ & $\begin{array}{l}100,0 \% \\
(0,00)^{\star \star}\end{array}$ & $\begin{array}{c}92,3 \% \\
(0,003)^{\star \star}\end{array}$ & $\begin{array}{l}100,0 \% \\
(0,00)^{\star \star}\end{array}$ & $\begin{array}{c}84,6 \% \\
(0,02)^{\star \star}\end{array}$ & $\begin{array}{l}100,0 \% \\
(0,00)^{\star \star}\end{array}$ & $\begin{array}{c}92,3 \% \\
(0,003)^{\star \star}\end{array}$ & $\begin{array}{l}100,0 \% \\
(0,00)^{\star \star}\end{array}$ & $\begin{array}{c}92,3 \% \\
(0,003)^{\star \star}\end{array}$ & $\begin{array}{l}100,0 \% \\
(0,00)^{\star \star}\end{array}$ \\
\hline Objetividade & $\begin{array}{c}92,3 \% \\
(0,003)^{\star \star}\end{array}$ & $\begin{array}{l}100,0 \% \\
(0,00)^{\star \star}\end{array}$ & $\begin{array}{c}84,6 \% \\
(0,02)^{\star \star}\end{array}$ & $\begin{array}{l}100,0 \% \\
(0,00)^{\star \star}\end{array}$ & $\begin{array}{c}92,3 \% \\
(0,003)^{\star \star}\end{array}$ & $\begin{array}{l}100,0 \% \\
(0,00)^{\star \star}\end{array}$ & $\begin{array}{c}53,8 \% \\
(0,70)^{\star \star}\end{array}$ & $\begin{array}{l}100,0 \% \\
(0,00)^{\star \star}\end{array}$ & $\begin{array}{c}84,6 \% \\
(0,02)^{\star \star}\end{array}$ & $\begin{array}{l}100,0 \% \\
(0,00)^{\star *}\end{array}$ \\
\hline Simplicidade & $\begin{array}{c}84,6 \% \\
(0,02)^{\star \star}\end{array}$ & $\begin{array}{l}100,0 \% \\
(0,00)^{\star \star}\end{array}$ & $\begin{array}{c}92,3 \% \\
(0,003)^{\star \star}\end{array}$ & $\begin{array}{l}100,0 \% \\
(0,00)^{\star \star}\end{array}$ & $\begin{array}{c}53,8 \% \\
(0,70)^{\star \star}\end{array}$ & $\begin{array}{l}100,0 \% \\
(0,00)^{\star \star}\end{array}$ & $\begin{array}{c}76,9 \% \\
(0,16)^{\star \star}\end{array}$ & $\begin{array}{l}100,0 \% \\
(0,00)^{\star \star}\end{array}$ & $\begin{array}{c}84,6 \% \\
(0,02)^{\star \star}\end{array}$ & $\begin{array}{l}100,0 \% \\
(0,00)^{\star \star}\end{array}$ \\
\hline Clareza & $\begin{array}{c}84,6 \% \\
(0,02)^{\star \star}\end{array}$ & $\begin{array}{l}100,0 \% \\
(0,00)^{\star \star}\end{array}$ & $\begin{array}{c}69,2 \% \\
(0,40)^{\star \star}\end{array}$ & $\begin{array}{c}88,8 \% \\
(0,009)^{\star \star}\end{array}$ & $\begin{array}{c}69,2 \% \\
(0,40)^{\star \star}\end{array}$ & $\begin{array}{l}100,0 \% \\
(0,00)^{\star \star}\end{array}$ & $\begin{array}{c}76,9 \% \\
(0,16)^{\star \star}\end{array}$ & $\begin{array}{c}88,8 \% \\
(0,009)^{\star \star}\end{array}$ & $\begin{array}{c}84,6 \% \\
(0,02)^{\star \star}\end{array}$ & $\begin{array}{l}100,0 \% \\
(0,00)^{\star \star}\end{array}$ \\
\hline $\begin{array}{l}\text { Relevância/ } \\
\text { pertinência }\end{array}$ & $\begin{array}{l}84,6 \% \\
(0,02)^{\star \star}\end{array}$ & $\begin{array}{l}100,0 \% \\
(0,00)^{\star \star}\end{array}$ & $\begin{array}{c}84,6 \% \\
(0,02)^{\star \star}\end{array}$ & $\begin{array}{l}100,0 \% \\
(0,00)^{\star \star}\end{array}$ & $\begin{array}{c}92,3 \% \\
(0,003)^{\star \star}\end{array}$ & $\begin{array}{l}100,0 \% \\
(0,00)^{\star \star}\end{array}$ & $\begin{array}{c}84,6 \% \\
(0,02)^{\star \star}\end{array}$ & $\begin{array}{l}100,0 \% \\
(0,00)^{\star \star}\end{array}$ & $\begin{array}{l}84,6 \% \\
(0,02)^{\star \star}\end{array}$ & $\begin{array}{l}100,0 \% \\
(0,00)^{\star \star}\end{array}$ \\
\hline Precisão & $\begin{array}{c}84,6 \% \\
(0,02)^{\star \star}\end{array}$ & $\begin{array}{l}100,0 \% \\
(0,00)^{\star \star}\end{array}$ & $\begin{array}{c}76,9 \% \\
(0,16)^{\star \star}\end{array}$ & $\begin{array}{l}100,0 \% \\
(0,00)^{\star *}\end{array}$ & $\begin{array}{c}76,9 \% \\
(0,16)^{\star \star}\end{array}$ & $\begin{array}{l}100,0 \% \\
(0,00)^{\star \star}\end{array}$ & $\begin{array}{c}92,3 \% \\
(0,003)^{\star \star}\end{array}$ & $\begin{array}{l}100,0 \% \\
(0,00)^{\star \star}\end{array}$ & $\begin{array}{c}84,6 \% \\
(0,02)^{\star \star}\end{array}$ & $\begin{array}{l}100,0 \% \\
(0,00)^{\star *}\end{array}$ \\
\hline Variedade & $\begin{array}{l}84,6 \% \\
(0,02)^{\star \star}\end{array}$ & $\begin{array}{l}100,0 \% \\
(0,00)^{\star \star}\end{array}$ & $\begin{array}{c}92,3 \% \\
(0,003)^{\star \star}\end{array}$ & $\begin{array}{l}100,0 \% \\
(0,00)^{\star \star}\end{array}$ & $\begin{array}{c}84,6 \% \\
(0,02)^{\star \star}\end{array}$ & $\begin{array}{c}88,8 \% \\
(0,009)^{\star \star}\end{array}$ & $\begin{array}{c}84,6 \% \\
(0,02)^{\star \star}\end{array}$ & $\begin{array}{c}88,8 \% \\
(0,009)^{\star \star}\end{array}$ & $\begin{array}{l}84,6 \% \\
(0,02)^{\star \star}\end{array}$ & $\begin{array}{l}100,0 \% \\
(0,00)^{\star \star}\end{array}$ \\
\hline Modalidade & $\begin{array}{c}69,2 \% \\
(0,40)^{\star \star}\end{array}$ & $\begin{array}{l}100,0 \% \\
(0,00)^{\star *}\end{array}$ & $\begin{array}{c}84,6 \% \\
(0,02)^{\star \star}\end{array}$ & $\begin{array}{c}88,8 \% \\
(0,009)^{\star \star}\end{array}$ & $\begin{array}{c}69,2 \% \\
(0,40)^{\star \star}\end{array}$ & $\begin{array}{c}88,8 \% \\
(0,009)^{\star \star}\end{array}$ & $\begin{array}{c}92,3 \% \\
(0,003)^{\star \star}\end{array}$ & $\begin{array}{l}100,0 \% \\
(0,00)^{\star \star}\end{array}$ & $\begin{array}{c}76,9 \% \\
(0,16)^{\star \star}\end{array}$ & $\begin{array}{l}100,0 \% \\
(0,00)^{\star \star}\end{array}$ \\
\hline Tipicidade & $\begin{array}{c}84,6 \% \\
(0,02)^{\star \star}\end{array}$ & $\begin{array}{l}100,0 \% \\
(0,00)^{\star \star}\end{array}$ & $\begin{array}{c}84,6 \% \\
(0,02)^{\star \star}\end{array}$ & $\begin{array}{l}100,0 \% \\
(0,00)^{\star \star}\end{array}$ & $\begin{array}{c}84,6 \% \\
(0,02)^{\star \star}\end{array}$ & $\begin{array}{l}100,0 \% \\
(0,00)^{\star \star}\end{array}$ & $\begin{array}{c}84,6 \% \\
(0,02)^{\star \star}\end{array}$ & $\begin{array}{l}100,0 \% \\
(0,00)^{\star \star}\end{array}$ & $\begin{array}{l}84,6 \% \\
(0,02)^{\star \star}\end{array}$ & $\begin{array}{l}100,0 \% \\
(0,00)^{\star \star}\end{array}$ \\
\hline Credibilidade & $\begin{array}{c}92,3 \% \\
(0,003)^{\star \star}\end{array}$ & $\begin{array}{l}100,0 \% \\
(0,00)^{\star \star}\end{array}$ & $\begin{array}{c}84,6 \% \\
(0,02)^{\star \star}\end{array}$ & $\begin{array}{l}100,0 \% \\
(0,00)^{\star \star}\end{array}$ & $\begin{array}{c}84,6 \% \\
(0,02)^{\star \star}\end{array}$ & $\begin{array}{l}100,0 \% \\
(0,00)^{\star \star}\end{array}$ & $\begin{array}{c}84,6 \% \\
(0,02)^{\star \star}\end{array}$ & $\begin{array}{l}100,0 \% \\
(0,00)^{\star \star}\end{array}$ & $\begin{array}{c}84,6 \% \\
(0,02)^{\star \star}\end{array}$ & $\begin{array}{l}100,0 \% \\
(0,00)^{\star \star}\end{array}$ \\
\hline Amplitude & $\begin{array}{c}92,3 \% \\
(0,003)^{\star \star}\end{array}$ & $\begin{array}{l}100,0 \% \\
(0,00)^{\star \star}\end{array}$ & $\begin{array}{c}84,6 \% \\
(0,02)^{\star \star}\end{array}$ & $\begin{array}{l}100,0 \% \\
(0,00)^{\star \star}\end{array}$ & $\begin{array}{c}84,6 \% \\
(0,02)^{\star \star}\end{array}$ & $\begin{array}{l}100,0 \% \\
(0,00)^{\star *}\end{array}$ & $\begin{array}{c}84,6 \% \\
(0,02)^{\star \star}\end{array}$ & $\begin{array}{l}100,0 \% \\
(0,00)^{\star \star}\end{array}$ & $\begin{array}{c}84,6 \% \\
(0,02)^{\star \star}\end{array}$ & $\begin{array}{l}100,0 \% \\
(0,00)^{\star \star}\end{array}$ \\
\hline Equilíbrio & $\begin{array}{c}84,6 \% \\
(0,02)^{\star \star}\end{array}$ & $\begin{array}{l}100,0 \% \\
(0,00)^{\star \star}\end{array}$ & $\begin{array}{c}84,6 \% \\
(0,02)^{\star \star}\end{array}$ & $\begin{array}{l}100,0 \% \\
(0,00)^{\star \star}\end{array}$ & $\begin{array}{l}84,6 \% \\
(0,02)^{\star \star}\end{array}$ & $\begin{array}{l}100,0 \% \\
(0,00)^{\star \star}\end{array}$ & $\begin{array}{c}92,3 \% \\
(0,003)^{\star \star}\end{array}$ & $\begin{array}{l}100,0 \% \\
(0,00)^{\star \star}\end{array}$ & $\begin{array}{c}84,6 \% \\
(0,02)^{\star \star}\end{array}$ & $\begin{array}{l}100,0 \% \\
(0,00)^{\star \star}\end{array}$ \\
\hline
\end{tabular}

"Teste Binomial;" $\rho \leq 0,05$

requisitos apresentaram concordância acima de 80,0\% e, foram estatisticamente significativos $(\rho \leq 0,05)$, no que tange a concordância entre os juízes. Novamente após as sugestôes dos juízes (Delphi II) foram necessárias modificaçóes apenas as medidas de prevenção "quanto ao dispositivo", de modo a torná-las mais clara, no item relativo a seleção do cateter periférico (CP) foi incluído: que possibilite menor frequência de troca e fluxo sanguíneo adequado e constante. A tabela 3 apresenta o consenso final entre as expertises em relação aos requisitos avaliados do conteúdo do bundle de condutas diante do extravasamento de AA que alcançaram concordância igual ou superior a "adequado", conforme os critérios de Pasquali.

Conforme o explanado na tabela 3, verificouse que, nas condutas gerais, específicas e no uso de antídotos e compressas frente ao extravasamento de AA, no Delphi I, os itens clareza $(76,9 \%)$ e modali-

Tabela 3. Consenso entre os juízes nas etapas Delphi I e II para os itens avaliados de conteúdo do bundle de condutas ao extravasamento de agentes antineoplásicos em pacientes oncológicos adultos

\begin{tabular}{|c|c|c|c|c|c|c|}
\hline \multirow{3}{*}{ Itens } & \multicolumn{6}{|c|}{ Condutas } \\
\hline & \multicolumn{2}{|c|}{ Gerais } & \multicolumn{2}{|c|}{ Específicas } & \multicolumn{2}{|c|}{ No uso de antídotos e compressas } \\
\hline & $\begin{array}{c}\text { Delphi I } \\
\left(\rho-\text { value }^{\star}\right)\end{array}$ & $\begin{array}{c}\text { Delphi II } \\
\left(\rho-\text { value }^{\star}\right)\end{array}$ & $\begin{array}{c}\text { Delphi I } \\
(\rho \text {-value* })\end{array}$ & $\begin{array}{c}\text { Delphi II } \\
\left(\rho-\text { value }^{\star}\right)\end{array}$ & $\begin{array}{c}\text { Delphi I } \\
\left(\rho-\text { value }^{\star}\right)\end{array}$ & $\begin{array}{c}\text { Delphi II } \\
\left(\rho-\text { value }^{\star}\right)\end{array}$ \\
\hline Comportamento & $84,6 \%(0,02)^{\star \star}$ & $88,8 \%(0,009)^{\star \star}$ & $92,3 \%(0,003)^{\star \star}$ & $100,0 \%(0,00)^{\star \star}$ & $92,3 \%(0,003)^{\star \star}$ & $100,0 \%(0,00)^{\star *}$ \\
\hline Objetividade & $84,6 \%(0,02)^{\star \star}$ & $88,8 \%(0,009)^{\star \star}$ & $92,3 \%(0,003)^{\star \star}$ & $100,0 \%(0,00)^{\star \star}$ & $84,6 \%(0,02)^{\star \star}$ & $100,0 \%(0,00)^{\star *}$ \\
\hline Simplicidade & $92,3 \%(0,003)^{\star \star}$ & $100,0 \%(0,00)^{\star \star}$ & $92,3 \%(0,003)^{\star \star}$ & $100,0 \%(0,00)^{\star \star}$ & $84,6 \%(0,02)^{\star \star}$ & $100,0 \%(0,00)^{\star *}$ \\
\hline Clareza & $76,9 \%(0,16)^{\star \star}$ & $100,0 \%(0,00)^{\star \star}$ & $76,9 \%(0,16)^{\star \star}$ & $88,8 \%(0,009)^{\star \star}$ & $76,9 \%(0,16) * \star$ & $88,8 \%(0,009)^{\star *}$ \\
\hline Relevância/pertinência & $84,6 \%(0,02)^{\star \star}$ & $100,0 \%(0,00)^{\star \star}$ & $84,6 \%(0,02)^{\star \star}$ & $100,0 \%(0,00)^{\star \star}$ & $84,6 \%(0,02)^{\star \star}$ & $88,8 \%(0,009)^{\star \star}$ \\
\hline Precisão & $92,3 \%(0,003)^{\star \star}$ & $100,0 \%(0,00)^{\star \star}$ & $84,6 \%(0,02)^{\star \star}$ & $100,0 \%(0,00)^{\star \star}$ & $84,6 \%(0,02)^{\star \star}$ & $100,0 \%(0,00)^{\star *}$ \\
\hline Variedade & $84,6 \%(0,02)^{\star \star}$ & $100,0 \%(0,00)^{\star \star}$ & $92,3 \%(0,003)^{\star \star}$ & $100,0 \%(0,00)^{\star \star}$ & $84,6 \%(0,02)^{\star \star}$ & $100,0 \%(0,00)^{\star \star}$ \\
\hline Modalidade & $76,9 \%(0,16)^{\star \star}$ & $100,0 \%(0,00)^{\star \star}$ & $76,9 \%(0,16)^{\star \star}$ & $88,8 \%(0,009)^{\star \star}$ & $76,9 \%(0,16)^{\star \star}$ & $100,0 \%(0,00)^{\star \star}$ \\
\hline Tipicidade & $84,6 \%(0,02)^{\star \star}$ & $100,0 \%(0,00)^{\star \star}$ & $92,3 \%(0,003)^{\star \star}$ & $100,0 \%(0,00)^{\star \star}$ & $92,3 \%(0,003)^{\star \star}$ & $100,0 \%(0,00)^{\star *}$ \\
\hline Credibilidade & $84,6 \%(0,02)^{\star \star}$ & $100,0 \%(0,00)^{\star \star}$ & $84,6 \%(0,02)^{\star \star}$ & $100,0 \%(0,00)^{\star *}$ & $84,6 \%(0,02)^{\star \star}$ & $100,0 \%(0,00)^{\star *}$ \\
\hline Amplitude & $92,3 \%(0,003)^{\star \star}$ & $100,0 \%(0,00)^{\star \star}$ & $92,3 \%(0,003)^{\star \star}$ & $100,0 \%(0,00)^{\star \star}$ & $92,3 \%(0,003)^{\star \star}$ & $100,0 \%(0,00)^{\star \star}$ \\
\hline Equilíbrio & $84,6 \%(0,02)^{\star \star}$ & $100,0 \%(0,00)^{\star \star}$ & $84,6 \%(0,02)^{\star \star}$ & $100,0 \%(0,00)^{\star \star}$ & $84,6 \%(0,02)^{\star \star}$ & $100,0 \%(0,00)^{\star \star}$ \\
\hline
\end{tabular}


dade $(76,9 \%)$ necessitaram de adequaçóes. Destacase que os itens supracitados não apresentaram significância estatística na concordância entre os juízes. As sugestôes dos juízes para as condutas gerais, específicas e no uso de antídotos e compressas foram quanto à sua forma de apresentação e realocação, ou seja, foi sugerido dividir em passos diferentes: relatar e registrar qualquer incidência envolvendo o extravasamento de AA e; registrar, por meio de fotografia, a imagem da área afetada, sendo que para tanto deverá haver consentimento por escrito do paciente. No Delphi II, nenhum dos itens teve CVC abaixo de 80,0\%, todos os requisitos analisados foram estatisticamente significativos $(\rho \leq 0,05)$ quanto a concordância entre as expertises. Os juízes não sugeriram mudanças na Delphi II em relação as condutas ao extravasamento de agentes antineoplásicos em pacientes oncológicos adultos. Ressalta-se que ao final do Delphi II, os dois módulos do bundle se apresentaram expressivamente válidos (prevenção do extravasamento de $\mathrm{AA}[\mathrm{CVC}=0,93]$ e condutas frente ao extravasamento $[\mathrm{CVC}=0,96])$.

\section{Discussão}

A construção e avaliação do conteúdo de um bundle de prevenção e condutas frente ao extravasamento de agentes antineoplásicos em pacientes oncológicos adultos foi desenvolvido com rigor metodológico para possibilitar que conhecimentos científicos fossem acessíveis para os profissionais de enfermagem que atuam nesses espaços.

Reconhece-se que à ausência de um registro centralizado de eventos de extravasamento de TA contribui para a incidência baixa documentada. ${ }^{(4,8)}$ $\mathrm{E}$, à medida que a quantidade de vazamento extravascular aumenta, o dano cutâneo resultante do extravasamento de AA fica menos propenso a cicatrizar. $^{(18)}$ Assim, atrasos na detecção de extravasamento podem levar a danos severos à pele, tornando a detecção o mais precoce possível e, o enfermeiro é o responsável pela infusão de TA, prevenção e gestão diante do extravasamento. ${ }^{(1,3,19)}$

Diante dessa conjuntura, torna-se de suma importância, a construção e a avaliação do bundle de- senvolvido neste estudo para a prevenção e o manejo diante do extravasamento de AA em pacientes oncológicos adultos nos mais diversos contextos oncológicos.

Ao formato inicial não foram acrescidos itens dos inicialmente elencados, o que infere que os especialistas consideraram suficientes os itens de verificação relativos à prevenção e condutas diante do extravasamento de AA e, as recomendações permitiram que se alcance o objetivo desejado, além da elevação na concordância e confiabilidade do instrumento.

Salienta-se que dos 57 itens distribuídos no primeiro módulo (medidas de prevenção do extravasamento de AA), as alteraçóes realizadas consistiram na clareza (nos itens relativos ao dispositivo adequado para punção, local da punção do acesso venoso e infusão de antineoplásicos), na modalidade (nos incisos quanto ao paciente, quanto à equipe de enfermagem e local da punção do acesso venoso), na precisão (nos itens relacionados ao dispositivo adequado para punçáo e local da punção do acesso venoso), na simplicidade e na objetividade (ambos no requisito local da punção do acesso venoso). No segundo módulo, relativo as condutas gerais, específicas e no uso de antídotos/compressas frente ao extravasamento de $\mathrm{AA}$, as mudanças foram em relação a clareza e a modalidade dos itens.

Em relação ao nível das evidências científicas dos itens do bundle, a maioria das publicaçóes era derivadas de um único estudo descritivo e/ou qualitativo (nível VI - 54,3\%) e, nenhuma evidência derivada de revisão sistemática ou metanálise de ensaios clínicos randomizados (nível I) e proveniente de ensaio clínico randomizado controlado bem delineado (nível II). Isto pode sugerir que a gestão de extravasamento está fundamentada em estudos descritivos, contudo, a falta de ensaios clínicos pode ser elucidada pela complexidade em garantir a legitimidade e confiabilidade, pela diversidade de variáveis e, especialmente, das ponderaçóes éticas que torna inviável a existência de um grupo de controle. Além das premissas de tamanho da amostra para pesquisas quantitativas desta natureza, a fim de produzir resultados estatisticamente significativos, devido ao número relativamente baixo e acontecimento espo- 
rádico de extravasamento de TA, tornando impraticável a concretização desse tipo de estudo. ${ }^{(6,8)}$

Neste estudo, ressalta-se a significativa experiência dos juízes participantes das etapas de avaliação, os quais eram doutores com elevada experiência prática na oncologia e na docência. Nesse sentido, a literatura expóe que mestres e doutores são os grandes responsáveis por possibilitar repercussóes nas práticas e, por conseguinte, no avanço da Enfermagem. ${ }^{(20)}$

Nessa perspectiva, estudo aponta que enfermeiros brasileiros com algum tipo de pós-graduação stricto sensu enquadram-se em uma realidade que é dirigida por políticas que consolidam e trazem inovaçóes em suas ações para a obtenção de impactos educacionais, sociopolíticos e científico-tecnológicos expressivos para a Enfermagem e para a Saúde. ${ }^{(21)}$ Isto posto, compreende-se que a participação de profissionais experientes e envolvidos no âmbito da pesquisa e do cuidado é relevante para avaliação de instrumentos a serem aplicados na prática, como se propôs este estudo ao avaliar um bundle na gestão do extravasamento de AA por enfermeiros.

O processo de avaliação envolveu a participação de 13 juízes no Delphi I (DI) e nove desses juízes no Delphi II (DII). A confiabilidade e a validade consistem em critérios primordiais para avaliação da qualidade de um instrumento. Nesse ínterim, a validade relaciona-se ao fato de um instrumento medir precisamente o que se propóe a medir. ${ }^{(18)}$ A confiabilidade é a capacidade em reproduzir um resultado de maneira congruente. Trata-se de um dos critérios principais de qualidade de um instrumento. ${ }^{(18,20)}$

Em relação a técnica Delphi usada para aquiescer consulta a um grupo de juízes especialistas no assunto, alcançou a meta de não deduzir a uma simples resposta ou chegar exclusivamente ao consenso, mas sim obteve opinióes e respostas de qualidade para uma dada indagação apresentada a um painel de especialistas, segundo recomendado pelo referencial metodológico. ${ }^{(12)}$

$\mathrm{Na}$ avaliação do bundle, os juízes apresentaram coeficiente de concordância significativo em todos os itens avaliados, de modo a tornar o instrumento válido em relação ao comportamento, objetividade, simplicidade, clareza, relevância, precisão, varieda- de, modalidade, tipicidade, credibilidade, amplitude e equilíbrio. ${ }^{(17)}$

As sugestóes dos juízes no bundle de prevenção de extravasamentos de TA, as solicitaçóes realizadas nas medidas de prevenção "quanto ao paciente", foram à adequação de vocabulário e, na ação relacionada a atentar-se aos fatores de risco, foi exemplificado as alteraçóes dérmicas que podem estar presentes, como: edema, desidratação, tônus e elasticidade alterados.

A identificação adequada dos fatores potenciais para o extravasamento é importante para minimizar o risco em alguns pacientes. Em caso de aumento do risco de extravasamento, medidas preventivas devem ser encorajadas ou, em alguns casos, a inserção de um dispositivo de acesso venoso central deve ser considerada. Esses fatores podem ser classificados em fatores de risco associados ao paciente e ao procedimento. ${ }^{(2)}$

Nas medidas preventivas "quanto ao dispositivo" e "quanto ao local da punção do acesso venoso", as sugestôes dos juízes foram de unir, realocar e condensar itens, para permitir a expressão de uma única ideia e a compreensão adequada, sem gerar ambiguidades. Nas açóes "quanto à equipe de enfermagem”, o vocabulário foi adequado. A literatura aponta que, na construção de protocolos e/ou bundles a adequação do vocabulário é essencial, devem ser construídos de forma a evitar vocábulos de pouca aplicação no processo de trabalho. ${ }^{(20,22)}$

No que se refere as ações "quanto à infusão" de TA foi recomendado a retirada do item: realizar a administração de antieméticos apenas após a TA, devido à ausência de evidência científica. As náuseas e vômitos induzidos por TA podem ser classificados em agudos, tardios ou antecipatórios, conforme o tempo de surgimento dos sintomas e, para a escolha adequada do antiemético, deve-se considerar o nível emetogênico dos AA utilizados e os fatores de riscos específicos do paciente, podendo ser utilizadas associaçóes. Várias diretrizes recomendam regimes antieméticos profiláticos para náuseas e vômitos. ${ }^{(23)}$

As sugestões dos juízes para as condutas gerais, específicas e no uso de antídotos e compressas foram quanto dividir o item relatar e registrar qualquer incidência envolvendo o extravasamento de AA e; a ação registrar, por meio de fotografia, a imagem da 
área afetada, sendo que para tanto deverá haver consentimento por escrito do paciente.

Ressalta-se que cada incidente de extravasamento deve ser documentado e relatado corretamente e; a documentação fotográfica é bastante útil para os procedimentos de acompanhamento e tomada de decisão, o paciente deve ser informado sobre o escopo do problema, se um AA vesicante tiver extravasado, informações sobre o tempo envolvido na resolução, bem como as implicaçóes legais. ${ }^{(2-4,6)}$

A literatura aponta que coeficiente de concordância aceitável entre os membros do comitê de especialistas deve ser de no mínimo 0,80 e, preferencialmente, maior que $0,90,{ }^{(18)}$ como verificado neste estudo (prevenção do extravasamento de antineoplásicos $[\mathrm{CVC}=0,93]$ e condutas frente ao extravasamento $[\mathrm{CVC}=0,96])$ e, tais variaçóes se mostraram significativas estatisticamente $(\rho \leq 0,05)$, o que comprova a obtenção de melhor consenso associado a melhorias do instrumento entre as rodadas de Delphi, além de o instrumento apresentar-se adequado para a aplicabilidade na prática de maneira confiável.

Apesar do apontado rigor na avaliação de conteúdo do bundle, necessita-se prosseguir com as etapas seguintes, para equivalência operacional e de mensuração. Para tanto, foi iniciada à sua aplicação em hospital de grande porte brasileiro, habilitado como Unidade de Assistência de Alta Complexidade em Oncologia (UNACON), a fim de que seja crível verificar sua eficiência.

A limitação deste estudo está relacionada ao baixo número de respostas dos peritos. Todavia, ressalta-se que a amostra de juízes foi constituída de número considerado adequado pelo referencial metodológico utilizado. ${ }^{(12)}$

Apesar disso, este estudo colaborará de maneira substancial para reforçar a atenção dos enfermeiros quanto a prevençáo e condutas frente ao extravasamento de agentes antineoplásicos em pacientes oncológicos adultos.

\section{Conclusão}

Os resultados obtidos no estudo da construção e avaliação do bundle de prevenção e condutas frente ao extravasamento de agentes antineoplásicos em pacientes oncológicos adultos apontaram propriedades psicométricas aceitáveis à sua utilização nos serviços de saúde oncológicos. $\mathrm{O}$ consenso dos juízes forneceu evidências para confiabilidade do bundle, com as alterações dos itens por eles recomendados. A avaliação do instrumento foi medida com desfecho significante, seguindo o rigor metodológico da técnica Delphi.

\section{Agradecimentos}

"O presente trabalho foi realizado com apoio da Coordenação de Aperfeiçoamento de Pessoal de Nível Superior (CAPES) - Código de Financiamento 001”.

\section{Colaborações}

Melo JMA, Oliveira PP, Rodrigues AB, Souza RS, Fonseca DF, Gontijo TF, Silveira EAA, declaram que contribuíram com a concepção do projeto, interpretação dos dados, revisão crítica relevante do conteúdo intelectual e aprovação da versão final a ser publicada.

\section{Referências}

1. Souza NR, Bushatsky M, Figueiredo EG, Melo JT, Freire DA, Santos IC. Oncological emergency: the work of nurses in the extravasation of antineoplastic chemotherapeutic drugs. Esc Anna Nery. 2017;21(1):e20170009.

2. Kreidieh FY, Moukadem HA, El Saghir NS. Overview, prevention and management of chemotherapy extravasation. World J Clin Oncol. 2016;7(1):87-97.

3. Jackson-Rose J, Del Monte J, Groman A, Dial LS, Atwell L, Graham J, et al. Chemotherapy Extravasation: establishing a national benchmark for incidence among Cancer Centers. Clin J Oncol Nurs. 2017;21(4):438-45.

4. Na Z, Qiaoyuan Y, Binghan W, Qin Z, Yue C, Xin P, et al. A developed model of cancer patients participation in intravenous chemotherapy safety. Oncotarget. 2017;8(50):87598-606.

5. Silva SM, Alves ID, Silva TM, Brandão CP, Santos AG. Levantamento dos índices de extravasamento de quimioterápicos no ambulatório de quimioterapia do centro de assistência de alta complexidade de oncologia (CACON) - HUPAA. GEP News. 2018;1(1):172-7.

6. Harrold K, Gould D, Drey N. The management of cytotoxic chemotherapy extravasation: a systematic review of the literature to evaluate the evidence underpinning contemporary practice. Eur $\mathrm{J}$ Cancer Care (Engl). 2015;24(6):771-800. 
7. Radael W, Radael W, Carvalho A, Dutra J, Lazarone B, Fumian L. Avaliação do risco de extravasamento de quimioterápico antineoplásico administrado via cateter de inserção periférica: relato de caso. Acta Biomed Bras. 2016;7(1):124-9.

8. Borgert M, Binnekade J, Paulus F, Goossens A, Dongelmans D. A flowchart for building evidence-based care bundles in intensive care: based on a systematic review. Int J Qual Health Care. 2017;29(2):163-75.

9. Silva $A G$, Oliveira AC. Impact of the bundles implementation on the reduction of bloodstream infections: an integrative review. Texto Contexto Enferm. 2018;27(1):e3540016.

10. Conselho Federal de Enfermagem. Resolução COFEN 569/2018. Aprova o Regulamento Técnico da Atuação dos Profissionais de Enfermagem em Quimioterapia Antineoplásica. [Internet]. Brasília (DF); 2018. [citado 2019 Mar 30]. Disponível em: http://www.cofen.gov.br/ resolucao-cofen-no-0569-2018_60766.html

11. Chera BS, Mazur L, Buchanan I, Kim HJ, Rockwell J, Milowsky MI, et al. Improving patient safety in clinical oncology: applying lessons from normal accident theory. JAMA Oncol. 2015;1(7):958-64.

12. Pasquali L. Instrumentação psicológica: fundamentos e práticas. Porto Alegre: Artmed; 2010.

13. Tricco AC, Lillie E, Zarin W, O'Brien KK, Colquhoun $H$, Levac D, et al. PRISMA Extension for Scoping Reviews (PRISMA-SCR): checklist and Explanation. Ann Intern Med. 2018;169(7):467-73.

14. Peters MD, Godfrey C, Mclnerney P, Baldini SC, Khalil H, Parker D. Scoping Reviews. In: Aromataris E, Munn Z, editors. Joanna Briggs Institute Reviewer's Manual. Adelaide (Australia): The Joanna Briggs Institute; 2017. Chapter 11.

15. Melnyk BM, Fineout-Overholt E. Evidence-based practice in nursing \& healthcare. A guide to best practice. 2nd ed. Philadelphia: Lippincot Williams \& Wilkins; 2011.
16. Fehring RJ. The Fehring model. In: Carrol-Johnson RM, Paquette M. Classification of nursing diagnoses: proceedings of the tenth conference of North American Nursing Diagnosis Association. Philadelphia: Lippincott; 1994.

17. Polit DF, Beck CT. Fundamentos de pesquisa em enfermagem: avaliação de evidências para a prática de enfermagem. 7th ed. Porto Alegre: Artmed; 2011.

18. Souza AC, Alexandre NM, Guirardello EB. Psychometric properties in instruments evaluation of reliability and validity. Epidemiol Serv Saude. 2017;26(3):649-59.

19. Matsui Y, Murayama R, Tanabe H, Oe M, Motoo Y, Wagatsuma T, et al. Evaluation of the predictive validity of thermography in identifying extravasation with intravenous chemotherapy infusions. J Infus Nurs. 2017;40(6):367-74.

20. Gomes AT, Alves KY, Bezerril MS, Rodrigues CC, Ferreira Júnior MA, Santos VE. Validation of graphic protocols to evaluate the safety of polytrauma patients. Acta Paul Enferm. 2018;31(5):504-17.

21. Scochi CGS, Munari DB, Gelbcke FL, Erdmann AL, Gutiérrez MGR, Rodrigues RAP. The strict sense nursing postgraduation in Brazil: advances and perspectives. Rev Bras Enferm. 2013;66(Spe):80-9.

22. Vieira CE, Enders BC, Coura AS, Menezes DJ, Lira AL, Medeiros CC. Validação de instrumento para o screening de adolescentes com excesso de peso na escola. Enferm Global. 2016;(43):33141.

23. Lee MA, Cho EK, Oh SY, Ahn JB, Lee JY, Thomas B, et al. Clinical practices and outcomes on chemotherapy-induced nausea and vomiting management in South Korea: comparison with Asia-Pacific data of the Pan Australasian chemotherapy induced emesis burden of illness study. Cancer Res Treat. 2016;48(4):1420-8.

\section{Apêndice 1. Referências utilizadas como fundamentação para a construção do bundle}

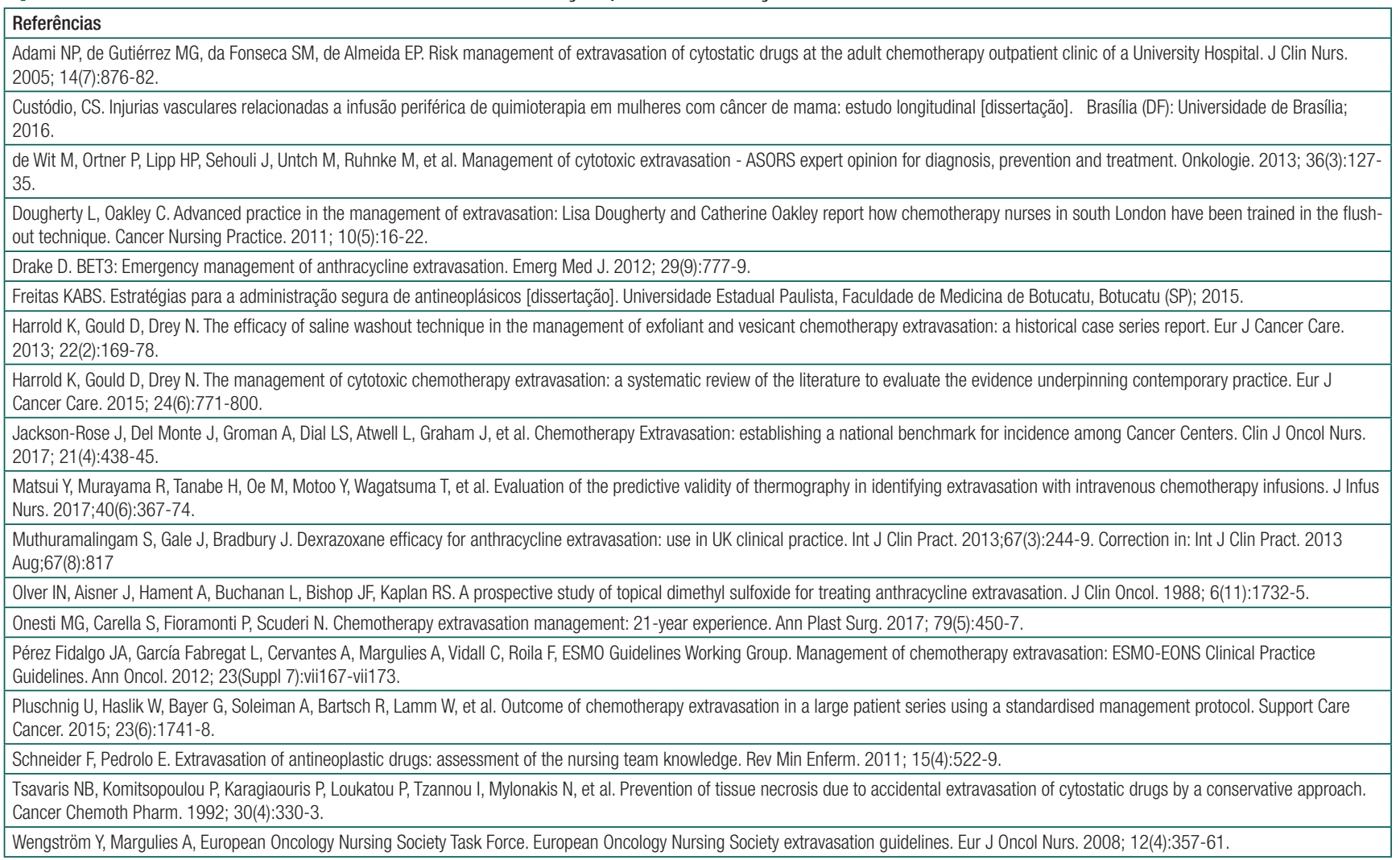




\begin{tabular}{|c|c|c|}
\hline \multicolumn{3}{|c|}{ Bundle de prevenção e condutas frente 0 extravasamento de agentes antineoplásicos } \\
\hline \multicolumn{3}{|c|}{ Prevenção Frente ao Extravasamento de Agentes Antineoplásicos (AA) } \\
\hline CONDUTA & Ações/Medidas & \begin{tabular}{|l} 
Nível de \\
Evidência
\end{tabular} \\
\hline \multirow[t]{5}{*}{$\begin{array}{l}\text { QUANTO AO } \\
\text { PACIENTE }\end{array}$} & $\begin{array}{l}\text { Atentar-se aos fatores de risco: presença de veias tortuosas, pouco calibrosas, obesidade, múltiplas punções venosas prévias, presença de alterações dérmicas } \\
\text { (como: edema, desidratação, tônus e elasticidade alterados), uso de medicamentos, alteração nutricional, movimentação do paciente (limitar ao máximo possível), } \\
\text { inconsciência e rebaixamento sensorial. }\end{array}$ & $\mathrm{VI}$ \\
\hline & Explicar ao paciente os possiveis riscos relacionados à infusão dos AA, incluindo vulnerabilidade para extravasamento. & V \\
\hline & Informar sobre as consequências do extravasamento de AA, assim como as formas de prevenção. & V \\
\hline & Aconselhar o paciente a relatar qualquer nível de dor, ardência, formigamento ou prurido, o que sugere infiltração perivenosa. & V \\
\hline & $\begin{array}{l}\text { Monitorar constantemente o paciente durante todo o período de infusão do AA, atentando para sinais e sintomas de extravasamento para além da dor, uma vez } \\
\text { que o limiar de dor difere de pessoa para pessoa (nunca subestimar as queixas de manifestações locais do paciente). }\end{array}$ & V \\
\hline \multirow[t]{4}{*}{$\begin{array}{l}\text { QUANTO AO } \\
\text { DISPOSITIVO }\end{array}$} & $\begin{array}{l}\text { Solicitar a implantação de acesso venoso central em casos de dificuldades na obtenção do acesso venoso periférico (necessite de até três tentativas para inserção } \\
\text { do cateter periférico), além de tratamento prolongado. } \\
\text { Nas novas recomendações da ANVISA o limite para tentativas de punção periférica são três. }\end{array}$ & $\mathrm{Vl}$ \\
\hline & $\begin{array}{l}\text { Optar, sempre que possível e junto com o médico, pelo uso de cateter venosas centrais (CVC), já que elas são confiáveis, produzem menor desconforto e reduzem } \\
\text { risco de extravasamento }\end{array}$ & $\mathrm{Vl}$ \\
\hline & 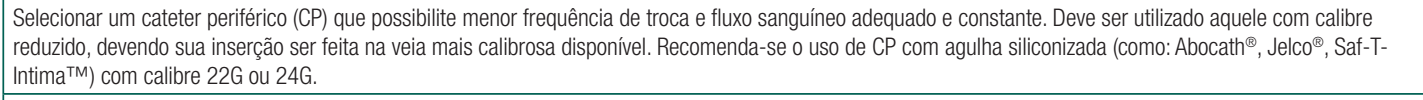 & $\mathrm{Vl}$ \\
\hline & $\begin{array}{l}\text { Dar preferência a cateteres de materiais flexíveis, tais como polietileno, siliconizado, Vialon }{ }^{\top M} \text {. Nunca utilizar cateter agulhado (scalp®) para a administração de } \\
\text { AA vesicante em via periférica. }\end{array}$ & VI \\
\hline \multirow{8}{*}{$\begin{array}{l}\text { QUANTO AO } \\
\text { LOCAL DE } \\
\text { PUNÇÃO }\end{array}$} & $\begin{array}{l}\text { Selecionar sítio de inserção do cateter venoso periférico, se for o caso, considerando segurança, reduzido riscos de extravasamento e fácil visualização, os locais } \\
\text { mais indicados para punção são as veias do antebraço. }\end{array}$ & VI \\
\hline & $\begin{array}{l}\text { Evitar puncionar: veias do dorso da mão (reduzida camada de tecido subcutâneo, proximidade com tendões, ossos e articulações); veias localizadas na fossa } \\
\text { antecubital (proximidade estruturas neurovasculares); veias dos membros inferiores. }\end{array}$ & $\mathrm{VI}$ \\
\hline & Inserir o cateter periférico, considerando o sentido do distal para o proximal. & VI \\
\hline & $\begin{array}{l}\text { Selecionar o local para a inserção do cateter venoso periférico considerando: (1) características da rede venosa (veias com pequeno calibre e/ou superficiais } \\
\text { devendo ser evitadas); (2) idade do paciente; (3) presença de diabetes; (4) uso de esteroides; (5) cateterizações venosas periféricas anteriores; (6) equimoses; (7) } \\
\text { hospitalização prévia e recente; (8) dissecção de linfonodos axilares ou linfedema; (9) doenças vasculares no membro escolhido; (10) presença de doenças que } \\
\text { alterem a percepção tátil sensorial do membro. }\end{array}$ & $\mathrm{VI}$ \\
\hline & Realizar a estabilização e cobertura segura do cateter utilizando filme transparente estéril e técnica asséptica, deixando o local da punção o mais visível possível. & IV \\
\hline & $\begin{array}{l}\text { Realizar flushing (lavagem com pressão do cateter) com solução fisiológica 0,9\% logo após a inserçãa do mesmo para testar sua funcionalidade. Durante a infusão } \\
\text { observar surgimento de edema local e relato de dor local pelo paciente. }\end{array}$ & IV \\
\hline & Monitorar rigorosamente o local de infusão a cada 5 a 10 minutos. & $\mathrm{VI}$ \\
\hline & Evitar a infusão de vesicantes por mais de 30 a 60 minutos, testando se o acesso está pérvio a cada 5 minutos durante a administração. & VII \\
\hline \multirow[t]{9}{*}{$\begin{array}{l}\text { QUANTO A } \\
\text { INFUSÃO }\end{array}$} & $\begin{array}{l}\text { Infundir o AA em sistema de linhas sem o uso de infusores de pressão ou bombas de infusão, uma vez que esses podem aumentar o risco de lesão por } \\
\text { extravasamento devido à elevaçãa da pressão nas camadas internas das veias. }\end{array}$ & VII \\
\hline & Realizar flushing (lavagem com pressão do cateter) com solução fisiológica 0,9\% após o término da administração. & $\mathrm{VI}$ \\
\hline & $\begin{array}{l}\text { Atentar-se para a administração de drogas que são incompatíveis e/ou possam causar sinergismo ou antagonismo entre elas e se for necessário realizar a troca } \\
\text { do equipo. }\end{array}$ & $\mathrm{VI}$ \\
\hline & Obter retorno de sangue antes da administração dos AA, certificando o posicionamento correto e seguro do cateter. & $\mathrm{VI}$ \\
\hline & Administrar drogas vesicantes por meio de equipos de gravidade ou em bolus. Nunca utilizar bomba de infusão. & VII \\
\hline & $\begin{array}{l}\text { Organizar a sessão de infusão de AA de modo que, quando houver prescrição de antineoplásico vesicantes este seja o primeiro a ser administrado, minimizando, } \\
\text { dessa forma, o risco de extravasamento. }\end{array}$ & VII \\
\hline & Administrar os AA lentamente, permitindo sua progressiva diluição no sangue. Nunca acelerar a infusão. & $\mathrm{VI}$ \\
\hline & Realizar a seleção de equipamento apropriado, como é o caso dos equipos e extensores. & $\mathrm{VI}$ \\
\hline & $\begin{array}{l}\text { Infundir solução fisiológica } 0,9 \% \text { a cada } 5 \text { minutos concomitantemente à administração em bolus do AA, evitando-se, dessa forma, picos de concentração dessas } \\
\text { drogas em contato com a parede endovascular. }\end{array}$ & $\mathrm{Vl}$ \\
\hline \multirow{6}{*}{$\begin{array}{l}\text { QUANTO A } \\
\text { EQUIPE DE } \\
\text { ENFERMAGEM }\end{array}$} & $\begin{array}{l}\text { Promover a qualificação permanente dos profissionais da equipe de enfermagem que atuam na administração de AA (enfatizando prevenção e gestão de } \\
\text { extravasamento). A conformidade com as recomendações do fabricante para cada medicamento deve ser assegurada. }\end{array}$ & IV \\
\hline & Atualizar regularmente as normas e políticas relativas à administração de AA vesicantes. & VI \\
\hline & Padronizar técnica de venopunção e de indicação correta de dispositivos de acesso vascular. & $\mathrm{VI}$ \\
\hline & Padronizar a diluição e a velocidade de infusão da droga; & VI \\
\hline & $\begin{array}{l}\text { Documentar, em prontuário, todas as etapas da sessão de AA, incluindo registros sobre as condições do paciente antes, durante e após a receber o AA, } \\
\text { orientações realizadas, local de inserção do cateter venoso, condições do acesso, a latência (período de resposta ao extravasamento) e as respostas do paciente, } \\
\text { bem como eventos de extravasamento, quando houver. }\end{array}$ & $\mathrm{Vl}$ \\
\hline & $\begin{array}{l}\text { Construir e implementar, de maneira conjunta com médicos e farmacêuticos do serviço, estratégias de redução de riscos e minimização de danos relacionados a } \\
\text { infusão de drogas vesicantes e irritantes. }\end{array}$ & $\mathrm{Vl}$ \\
\hline \multicolumn{3}{|c|}{ Condutas Frente ao Extravasamento de Agentes Antineoplásicos (AA) } \\
\hline \multicolumn{3}{|c|}{ Instruções Gerais } \\
\hline PASSOS & Ações/Medidas & $\begin{array}{l}\text { Nível de } \\
\text { Evidência }\end{array}$ \\
\hline 1 & Lembrar que após a prevenção, o reconhecimento imediato é a segunda melhor medida no tratamento de extravasamentos de AA. & IV \\
\hline 2 & $\begin{array}{l}\text { Atentar-se aos sinais e sintomas de extravasamento que incluem edema, hiperemia e / ou desconforto local, frequentemente descrito como uma sensação de } \\
\text { 'ardor' ou 'ardência'. Outas evidencias que podem indicar o extravasamento de AA incluem a presença de resistência para a introdução da droga na via, infusão } \\
\text { lenta da droga na rede vascular e ausência de retorno de sangue do cateter venoso. }\end{array}$ & VI \\
\hline
\end{tabular}




\begin{tabular}{|c|c|c|}
\hline 3 & Identificar o extravasamento do AA, logo em seguida, deve-se interromper imediatamente sua infusão. & IV \\
\hline 4 & Comunicar prontamente o evento ao enfermeiro responsável pelo setor. & VII \\
\hline 5 & Aspirar de 3 a 5 ml de sangue com a cânula ainda no local de infusão. & IV \\
\hline 6 & $\begin{array}{l}\text { Após aspirar a cânula, deve-se investigar se há antídotos espećf́icos e administrá-lo, quando houver, conforme recomendações da tabela que se segue (Instruções } \\
\text { específicas). Os antídotos devem ser administrados dentro da primeira hora após a identificaçã̃o do extravasamento. A administração dos antídotos deve ser tópica } \\
\text { (ao redor do local onde ocorreu o extravasamento), por via subcutânea, endovenosa ou tópica, conforme instruções específicas ou prescrição médica. }\end{array}$ & III \\
\hline 7 & Manter o membro comprometido elevado visando manutenção da absorção e drenagem de fluidos extravasados loculados. & IV \\
\hline 8 & $\begin{array}{l}\text { Promover o resfriamento ou aquecimento do local comprometido, de acordo com a tabela de instruções específicas, por pelo menos 15-30 minutos, quatro vezes } \\
\text { ao dia, por } 24-48 \text { horas. }\end{array}$ & $\mathrm{VI}$ \\
\hline 9 & $\begin{array}{l}\text { Relatar e registrar qualquer incidência envolvendo o extravasamento de AA. No registro deve constar a data e a hora do incidente, o nome do paciente, o nome } \\
\text { do medicamento, as características da solução infundida, a via de infusão utilizada, a descrição das características da área comprometido, os sinais e sintomas } \\
\text { presentes e o manejo realizado. Sugere-se registrar, por meio de fotografia, a imagem da área afetada, sendo que para tanto deverá haver consentimento por } \\
\text { escrito do paciente. }\end{array}$ & VI \\
\hline 10 & $\begin{array}{l}\text { Registrar, por meio de fotografia, a imagem da área afetada, sendo que para tanto deverá haver consentimento por escrito do paciente. Essa ação ajuda no } \\
\text { acompanhamento do progresso e do processo de cura da potencial lesão. }\end{array}$ & IV \\
\hline 11 & $\begin{array}{l}\text { Monitorar rigorosamente o local do extravasamento nas primeiras } 24 \text { horas após o incidente, seguindo o acompanhamento conforme necessário, avaliando os } \\
\text { sinais de dor, hiperemia, edema, ulceração ou necrose, dependendo da extensão do dano tecidual. }\end{array}$ & VI \\
\hline 12 & $\begin{array}{l}\text { Quando houver suspeita de extravasamento, o paciente deve ser monitorado, por meio de ligação telefônica, de } 1 \text { a } 3 \text { dias após o incidente. Caso o profissional } \\
\text { que realizou o telefonema suspeite de complicações, com base no relato do paciente, recomenda-se que o paciente seja orientado a procurar o ambulatório de } \\
\text { referência para uma avaliação especializada. Quando o extravasamento tiver sido confirmado, consultas de acompanhamento devem ser organizadas para avaliar } \\
\text { o local no } 2^{\circ}, 5^{\circ}, 7^{\circ}, 14^{\circ} \text { e continuar até que o paciente esteja totalmente recuperado. }\end{array}$ & |III \\
\hline 13 & Realizar a notificação do extravasamento à ANVISA, por meio do formulário de notificação de evento adverso preenchido do NOTIVISA. & VII \\
\hline \multicolumn{2}{|c|}{ Modo de aplicação dos antídotos / compressas quentes e frias } & $\begin{array}{l}\text { Nível de } \\
\text { Evidência }\end{array}$ \\
\hline \multicolumn{2}{|r|}{$\begin{array}{l}\text { A hialuronidase em injeção subcutânea. Administrar 150-900 Ul ao redor da área de extravasamento, ou seja, administrar } 1 \mathrm{~mL} \text { da solução de hialuronidase em cinco injeções de } 0,2 \\
\mathrm{~mL} \text { via subcutânea no local do extravasamento usando um calibre } 25 \text { ou agulha menor, trocando a agulha para cada injeção. }\end{array}$} & VI \\
\hline \multicolumn{2}{|r|}{$\begin{array}{l}0 \text { tiossulfato de sódio. Para preparar uma solução 1/6 molar, misture } 4 \text { mL de tiossulfato de sódio a 10\% com } 6 \text { mL de água estéril para injeção. Injete a solução no local do } \\
\text { extravasamento usando uma agulha de calibre } 25 \text { ou menor, trocando a agulha por cada injeçẫo. }\end{array}$} & IIII \\
\hline \multicolumn{2}{|c|}{$\begin{array}{l}0 \text { DMSO tópico (99\%) aplicar topicamente na pele duas vezes o tamanho da infiltração com um cotonete e deixe secar (não cubra). Comece o mais cedo possível (de preferência nos } \\
\text { primeiros } 10 \text { minutos). Deve ser aplicado a cada } 8 \mathrm{~h} \text { durante } 7 \text { dias. }\end{array}$} & |III \\
\hline \multicolumn{2}{|r|}{$\begin{array}{l}\text { Dexrazoxane: é o único tratamento que recebeu autorização da Comissão Europeia e aprovação da Food and Drug Administration dos EUA para o tratamento de extravasamento de } \\
\text { antraciclina. Administrar por via intravenosa em uma veia em uma área longe do local do extravasamento. Infundir } 1.000 \mathrm{mg} / \mathrm{m}^{2} \text { dentro de } 6 \mathrm{~h} \text { de extravasamento no Dia } 1,1.000 \mathrm{mg} / \\
\mathrm{m} 2 \text { no Dia } 2 \text { e } 500 \mathrm{mg} / \mathrm{m} 2 \text { no Dia 3. A dose diária máxima é de } 2.000 \mathrm{mg} \text {. }\end{array}$} & III \\
\hline \multicolumn{2}{|c|}{$\begin{array}{l}\text { Tratamento térmico: a aplicação de compressas frias baseia-se na indução de vasoconstrição com consequente diminuiçãa da velocidade de difusão do fármaco dentro dos } \\
\text { tecidos, reduzindo a área de potencial dano tecidual. O mecanismo de ação do calor aplicado ao local do extravasamento é induzir vasodilatação e, consequentemente, facilitar } \\
\text { o aumento da absorção e distribuição sistêmica do fármaco citostático. }\end{array}$} & $\mathrm{Vl}$ \\
\hline \multicolumn{2}{|r|}{$\begin{array}{l}\text { A aplicação de compressa quente deverá ser realizada durante } 20 \text { minutos, } 4 \text { vezes por dia durante } 1 \text { ou } 2 \text { dias somente para AA classificadas como alcaloides da vinca e a } \\
\text { Oxaliplatina. }\end{array}$} & $\mathrm{Vl}$ \\
\hline \multicolumn{2}{|r|}{ Os pacientes devem ser orientados a colocarem bolsa de gelo ou compressa fria por 15 a 20 minutos, 4 vezes ao dia durante as primeiras 24 horas para AA irritantes. } & VI \\
\hline
\end{tabular}

